\title{
INTRODUCTION TO THE HANDBOOK OF RESEARCH METHODS ON CREATIVITY
}

\author{
Viktor Dörfler and Marc Stierand
}

\section{RESEARCHING CREATIVITY}

This introduction is an attempt to prepare our readers for an exceptional journey into the fascinating landscape of research methods used to study the remarkable phenomenon of creativity. Building on what is already available about research methods on creativity, we explain what we were trying to achieve, how we went about it, and why we are proud of what we have achieved - primarily through the work of our contributors to this handbook. Most of this introduction is dedicated to brief descriptions of the chapters of the book. At the end, we make some suggestions for using this edited volume.

Creativity research has significantly matured in recent years, resulting in a wide variety of models and views of creativity (see Runco, 2019 for a recent comprehensive overview). Scholarly interest in creativity has gone mainstream, and dedicated creativity journals such as Journal of Creative Behavior, Creativity Research Journal, Thinking Skills and Creativity, Creativity and Innovation Management, and Psychology of Aesthetics, Creativity, and the Arts are actively competing with more general psychology and management journals to publish the best and most interesting creativity research. In addition, the topic of creativity is becoming popular in a variety of other disciplines, such as biology and neuropsychology (Shiu, 2014).

This development is, after all, also the result of methodological advancements. Accordingly, there is growing interest in demonstrating methodological sophistication to exhibit excellence. In response to this rising demand, a number of methodological textbooks on creativity research have been published. Some of these textbooks concentrate on a particular aspect of creativity (e.g. Lebuda \& Glăveanu, 2019) or focus on a single method (e.g. Savransky, 2000). However, none of them offers a broad methodological compendium of creativity research in management and organization studies (MOS).

There are also several reviews available of the different methodological approaches adopted in creativity research (see e.g. Long, 2014 for a comprehensive review). What we felt was missing was a book that paints with broad brushstrokes a complete picture of the methodological landscape 
of creativity research. Of course, such a book cannot discuss in detail every single method, and we did not seek to achieve this. What we want to see is a complete, if somewhat vague, picture of the overall methodological landscape while highlighting several fascinating points of interest. Indeed, we aim to provide enough markers to better orient those who wander into that landscape. We feel that we have achieved this purpose, thanks to the contributors of the included chapters.

This means that the ambitious purpose of this volume is to be a methodological reference book for the global community of creativity researchers in MOS as well as neighbouring disciplines such as psychology and sociology. Such a reference book, in line with what we said above, cannot be a methodological textbook, rigorously categorising and spanning all methods used by creativity researchers. Rather, as editors of this volume, and in consultation with our expert contributors, we have drawn together an eclectic collection of excellent chapters and vignettes. Chapters typically provide a detailed analysis of a particular methodological topic, considering its applicability, benefits and limitations, scope of validity, ethical implications and any other relevant aspects. Vignettes, in contrast, are exceptionally sharp, to-the-point pieces, similar to parables, with the aim of making the reader think. In both cases, we aimed for a balance of quantitative, qualitative and mixed approaches that address the phenomenon of creativity at individual, team or organizational levels, and we provided space for established methods as well as new approaches.

We did achieve what we wanted, and then we faced the arduous task of grouping these contributions. On the one hand, each chapter of this handbook could be a category on its own. On the other hand, most of the chapters would belong to more than one category, regardless of how the categories were formulated. So, we ended up with four categories: conceptual, design, qualitative and quantitative chapters. Most chapters in both the qualitative and the quantitative groups also address some conceptual and/or research design issue. Every chapter in research design also has something to say at a conceptual level, and most are aligned with some specific quantitative and/or qualitative methods. Finally, most conceptual chapters have something to contribute to at least one of the other three categories. The reason is not that we did not make the effort to figure out a better grouping or that the chapters are misfits in any sense. Quite to the contrary, we believe that the chapters are excellent, and they make contributions at multiple levels.

The reason for the necessary failure of any grouping is the nature of the methodological landscape. It only happens in classrooms that methods can be neatly categorised and put into boxes. The reality is that methodological approaches are multidimensional: methods get established, then changed, sometimes adapted to different conceptual, meta-theoretical or philosophical positions; new tools are invented all the time; and we continuously learn new things about existing items in 
the methodological toolbox. In other words, the methodological landscape is a mess. However, it is a rich mess. Individuals who have the tools to find their way through the mess will be amazed by the beauty of this landscape. The purpose of this book is to become such tool for orientation. It was a humbling experience to edit this volume - we do have substantial experience of the methodological questions of creativity research, but we also continuously find out how many methodological questions are located beyond what we know. Therefore editing this volume was also a great learning experience. We hope that it will also be a great learning experience for our readers.

Due to the complexity and variety of methodological contributions, we gave our contributors little in the way of guidelines; if anything, we encouraged them to reflect on their own experience and share their learning points with the readers of this volume. Each substantive chapter therefore adopts its own structure appropriate to explicate the authors' argument. We believe that no technique or methodological approach is superior to any other, whether quantitative or qualitative, used alone or in combination. Rather, we think that the selection of method or methodological approach depends on the context, the research topic and the investigator. We therefore gave our contributors as much freedom as possible to discuss and reflect on their own experiences of using a particular method or approach, with the aim to inspire and inform their readers about what is truly essential for the understanding and advancing of researching creativity in MOS at a conceptual or applied level.

We believe that what can be learned from the contributions and the way we brought them together in this volume is that the methods and research approaches we use or may develop for researching creativity need to do justice to the phenomenal complexity of creativity itself. That is, we should not methodologically cripple the reality of creativity if we expect to achieve valid and meaningful results and findings. Overall, this handbook provides us with the chance to reflect on how much creativity research has progressed, and to identify the more or less weak signals coming from the future avenues of creativity research that are currently in the process of being built. For us, after having engaged with our expert contributors via emails or conversations, and having read and commented on their drafts, the future of creativity research will need to enhance the precision and variety of creativity concepts while developing new research methods. In turn, this will help us recognise creativity and those teaching methods that can help develop creativity. Creativity has been for too long banished from formal education.

The book has 25 substantive contributions: 23 chapters and 2 vignettes. We have organised these into four categories, forming the four parts of the volume: Conceptual Issues ( 6 chapters), Research Design ( 4 chapters), Qualitative Research ( 5 chapters + 1 vignette) and Quantitative 
Research ( 8 chapters +1 vignette). In what follows, we briefly describe each contribution, organising them according to the four parts of the book.

\section{PART I CONCEPTUAL ISSUES}

Robert Sternberg provides a reflective personal account of his research into creativity. However, this intellectual autobiography also covers the history of the field; more precisely, it provides a personal take on how creativity research has evolved over the past quarter century.

Mark Runco reviews the ways in which creativity researchers have dealt with subjectivity, highlighting areas where subjectivity has caused problems for research and where specific types of objectivity may have misguided the research in attempts to maximise objectivity rather than achieve a more realistic and nuanced understanding of creativity.

Ronit Kark, Olga Epitropaki and Charalampos Mainemelis explore the research methods used in three distinct contexts of creative leadership, showing that distinct kinds of methods have been used due to contextual and focal differences. The authors further discuss the need for more diversity and flexibility in the use of methods in order to increase our understanding of the complexities of creative leadership.

Marie-Léandre Gomez and Isabelle Bouty offer a philosophical take on studying creativity as a practice using the approach of Pierre Bourdieu. This philosophical approach is an applied one, as the authors demonstrate through the example of studying Manet's artistic creativity.

Alexander Kofinas and Sandar Win also adopt a philosophical perspective, looking into mainstream literature reviews on creativity published by some of the most highly ranked management and organisation journals. They end up conceptualising what they call the 'ontological mythology of creativity'.

Marta Sinclair and Fabrizio Maimone look into a narrow aspect of creativity research, namely the role of intuition. However, within this narrow scope, they take a very broad view, exploring thematic trends relevant to intuition as well as methodological trends, painting a picture of the future in the making. 


\section{PART II RESEARCH DESIGN}

Eugene Sadler-Smith and Tim Wray explore the usefulness of abductive reasoning in studying creativity in a Peircean and pragmatic framing. In their argument, the authors draw parallels between deduction, induction and abduction, offering a comparative framework. The chapter ends by exploring the significance of intuition and insight.

On the basis of process philosophy, Robert Chia considers creativity-in-practice to be flitting between order and disorder, while challenging some aspects of what we typically understand by order and disorder. Bringing together the notions of empirical sensitivity and habitus, the author argues that we can find creativity in organisational everydayness even if it sometimes looks routine at first sight.

Nicole Rosenkranz and Michiel Tempelaar first examine the 'nestedness' of creative problem solving, distinguishing between top-down, bottom-up and 'bathtub' approaches. Based on this distinction they develop their multi-level survey design, discussing conceptual underpinnings and practicalities as well as the problem of validity.

Laureline Chiapello presents her adventure of struggling to develop a pragmatist research design to studying the creativity in video game design. This highly reflective account takes the reader through steps that iteratively combine philosophy and practicalities, gradually developing an understanding of creativity in this iterative methodological journey.

\section{PART III QUALITATIVE RESEARCH}

Based on a 35-year reflection, John Baer introduces the Consensual Assessment Technique (CAT) as the 'gold standard' of creativity assessment, as it avoids many of the disadvantages of other creativity assessment techniques, shows a transparent validity and is not confined to a particular theoretical framework of creativity. Yet, it is more time consuming to administer and requires human expert judges.

In his creative vignette, David Boje looks at Walter Benjamin's 1928 book One-Way Street, which deals with the question 'What future of modernity is arriving?' Boje sees in Benjamin's story a research method that he describes as antenarrative foresight, a kind of prospective sensemaking whereby, through 'presencing', Benjamin anticipates the future. 
Christian Grahle and Paul Hibbert adopt a practice lens to examine the ethnographic approach to studying creativity. Their focus is on capturing the creative process, and they discuss the difficulties of this focus. After discussing the benefits of applying a practice-based approach to rich ethnographic data, they look into the practicalities of application and the importance of reflexivity.

Michael Hanson and Vlad Glăveanu focus on the importance of case studies and the evolving systems approach. They do not see case studies as an alternative to surveys, psychometric experimental or historiometric research, but as an indispensable ally of these alternative designs. The unifying aim of all these approaches is achieving a better understanding of creativity.

Using metaphors both to represent and understand creativity, Heather Cairns-Lee outlines the importance of meta-creativity in researching creativity. She puts particular emphasis on researcher reflexivity and on fully revealing assumptions through metaphors, which, in turn, can be elicited through Clean Questions.

José-Rodrigo Córdoba-Pachón brings together Mihaly Csikszentmihalyi's systemic view of creativity with Soft-System Methodology, particularly its Rich Picture (RP) component. To demonstrate how RP can be used for studying creativity in a systemic view, the author offers a worked example researching educators' creativity.

\section{PART IV QUANTITATIVE RESEARCH}

To kick off this part, Ronald Beghetto and Maciej Karwowski contribute a much-focused vignette, highlighting the importance of clearly identifying the specific beliefs that researchers want to measure when studying creative confidence beliefs and how they influence creative behaviour.

Selcuk Acar, Uzeyir Ogurlu and Mark Runco's chapter identifies and offers solutions to major issues connected with meta-analysis, a method that can account for cultural and individual differences in researching the phenomenon of creativity.

Kerrie Unsworth and Mark Robinson present the methodological background of survey scales, their advantages and disadvantages for measuring creativity, and the implications for researchers. Then, based on data, they discuss validity, reliability and overlaps of the most frequently used creativity survey scales.

David and Arthur Cropley introduce the Innovation Phase Model, a measurement model that explains why and when seemingly exclusive states of the building blocks of Process, Person 
(Motivation), Person (Properties), Person (Feelings), Product and Press shape or constrain innovation and firm performance.

Roni Reiter-Palmon and Madison Schoenbeck provide an overview of the diverse ways in which creativity is measured. They alert us that the way in which creativity is measured influences our understanding of creativity. They go on to assert that measures of creativity are not easily interchangeable, if interchangeable at all.

Michael Mumford and Cory Higgs explain, by means of their tripartite model of the requirements for effective leadership, how creativity can be researched using historiometric studies and low-fidelity simulation methods. They argue that by using multiple methods we can increase the robustness of our studies of creativity.

Paul Sowden, Andrew Pringle and Matthew Peacock discuss the usefulness of analysing verbal protocols created by asking participants to 'think aloud' for understanding the creative process. They argue that the method can be used in practically any real-world creative situation.

Through a series of worked examples, Giovanni Formilan, Simone Ferriani and Gino Cattani introduce a method called Social Sequence Analysis (SSA), which they use to the study creative trajectories. They use a variety of techniques to visualise the evolution of creativity along multiple dimensions.

Jan Dul, Maciej Karwowski and James Kaufman present Necessary Condition Analysis (NCA), which is profoundly different from more traditional data analysis methods as it sees cause-effect relations as being 'necessary but not sufficient'. Therefore, NCA can help produce more structured theorising of the effects and conditions of creativity.

\section{ENGAGING WITH THIS BOOK}

We see two opposite ways in which you, the readers, can initially engage with this book. The first one would be to read it from cover to cover, almost using it as a textbook. This can be very useful, as long as you keep in mind that this is not a textbook. It does not have the well-defined but potentially rigid structure; in other words, it does not squeeze methods and approaches into 'boxes'. Instead, the methods discussed in it are more like gravitational points that attract you to a varying degree: some methods will feel closer to you, some further away. The opposite way of engaging with the book would be to browse the brief descriptions in this introduction, find only the one method you 
are interested in, and read about it. Similarly to the previous way, this can be a very useful approach as long as you keep in mind that this is not a textbook. You may be interested in a particular method that is not covered in these pages; and, if you do find a particular method in here, it may be that what is discussed contradicts or does not fully cover the same topic like an exhaustive textbook would. The reason for this is that we were obsessed with presenting the material from the point of view of the research practitioner. To do so, we wanted you to hear from people who have done research on creativity and see what they can say about their favourite method(s). We believe that you will find this approach useful.

We want to make a suggestion for using this book: read the whole volume first, even if not word for word. In reading it cover to cover, you will perceive a rich picture of the full landscape. Make up your mind (not as a final but as an initial choice) as to what method you would be interested in using. Regardless of whether the particular method is covered in this volume, you will likely find a few relevant methods - read these chapters more carefully. It is not so much about directly building on our contributors' experiences with that particular method; what you should focus on is how to ask questions about the suitability of that method, how to figure out whether it works for you, etc. In other words, focus on the questions rather than on the answers in relation to your chosen method and similar ones. The essence of this approach is something you can definitely see in this handbook: there are no right or wrong methods. What matters is finding the ones you can use. Our purpose with this handbook was to help you ask your own questions, find your own answers, make your own choices - so that you develop your own sound methodological approach with which you can conduct excellent research on creativity. And do not forget: you should have fun reading this book.

\section{REFERENCES}

Lebuda, I. \& Glăveanu, V. P. (Eds.). 2019. The Palgrave handbook of social creativity research. Cham, Switzerland: Palgrave Macmillan.

Long, H. 2014. An empirical review of research methodologies and methods in creativity studies (2003-2012). Creativity Research Journal, 26(4): 427-438. DOI:

$10.1080 / 10400419.2014 .961781$

Runco, M. A. 2019. Creativity: Research, development, and practice (3rd ed.). New York: Academic Press. 
Savransky, S. D. 2000. Engineering of creativity: Introduction to triz methodology of inventive problem solving. Boca Raton, FL: CRC Press.

Shiu, E. (Ed.). 2014. Creativity research: An inter-disciplinary and multi-disciplinary research handbook: London: Taylor \& Francis. 